\title{
Risk Analysis Model Using UML and MADS Model
}

\author{
Hafida Bouloiz $^{1}$, Emmanuel Garbolino ${ }^{2}$, Mohamed Tkiouat ${ }^{3}$ \\ ${ }_{1}^{1}$ Industrial Engineering Department, National School of Applied Sciences, E.N.S.A., Agadir, Morocco \\ ${ }^{2}$ Crisis and Risk Research Centre, Mines ParisTech, \\ Sophia Antipolis, France \\ ${ }^{3}$ Industrial Engineering Department, Engineers' Mohammadia School, Rabat, Morocco \\ E-mail: bouloizhafida@yahoo.fr,emmanuel.garbolino@mines-paristech.fr, tkiouat@emi.ac.ma \\ Received October 24, 2011; revised November 17, 2011; accepted November 25, 2011
}

\begin{abstract}
The purpose of this paper is to propose a model of risk analysis which combines two tools belonging to a different context. These both tools are MADS (Model of Analysis of Dysfunctional Systems) and UML (Unified Model Language). The proposed method aims to integrate UML language, especially the collaboration diagram, in the MADS model. We represent the danger source system of MADS model with the collaboration diagram in order to define and model the scenarios of risk. The application of this method is illustrated with an example of a storage unit of chemicals. On the one hand, the proposed model provides a comprehensive view that facilitates the understanding of the organization of an industrial system, and on the another hand, it leads to more effective analysis of risks taking into account the interactions between the system components.
\end{abstract}

Keywords: Risk Analysis, Safety, MADS Model, UML, Interactions, Collaboration Diagram

\section{Introduction}

Industrial processes, particularly chemical industries, are almost daily news headlines with the existence of potential risks that could cause accidents, considering the hazardous nature of the chemicals. Indeed, zero risk does unfortunately not exist in these industrial activities. This explains the large number of methods of risk analysis that have been developed in order to control the risks. Many studies describe the content of these methods of risk analysis such as [1-9]. Most of these methods are from field of dependability. Among of these methods: Hazard and Operability Study-HAZOP [6], Failure Mode Effect analysis-FMEA (24), Fault Tree Analysis-FTA [10], Preliminary Risks Analysis-PRA [6,11].

The occurrence of industrial accidents such as Bhopal (1984), Piper Alpha (1988), Chernobyl (1986), Seveso (1976), Mexico gas explosion (1984), Three Mile Island (1979), has shown the limits of these methods which describe an accident by the a series of events linked by cause and effect and does not take into account the interactions within the system so the complexity of a system. They do not give a good understanding of risks in the complex systems. According to [12], system is "a set of interacted elements". A similar view comes from organizational theory, where an industrial system is regarded as complex as its parts are in interactions [13]. Complex systems are characterized by emergent behavior due to interactions between the various components of the system seen at different levels of organization [14].

The goal of risk analysis is to define and identify the measures of risk control. It is the important step in the process of risk control and industrial safety. Therefore, risk analysis must take into account the complexity of system; especially that complex system is subject of accidents caused by dysfunctional interactions between system components [15]. In this context, the systemic approach is the demarche which allows analyzing the system and to formalize the interactions between its components. This approach, appeared at the end of 1960 [16], is an interdisciplinary joint makes it possible to understand and describe the complexity and it became an approach, a language or technical ensuring the modeling of complex systems.

This paper proposes a new model of risk analysis which contains two systemic tools which are UML model (Unified Modeling Language) and MADS model 
(Analysis Method of Dysfunctional Systems). The purpose of this approach is to integrate UML formalism, especially collaboration diagram in the MADS model. We represent the danger source system of MADS model with collaboration diagram in order to define risk scenarios. A comparison between UML and MADS model in the context of industrial risk analysis has been described in [17].

This paper is organized as follow: Section 2 presents and defines the two tools corresponding to MADS model and UML language. Section 3 present case study which is a storage unit of chemicals. In Section 4, we present proposed approach and it illustration through the case study, and Section 5 concludes the paper.

\section{Proposed Method}

The proposed method is founded on the UML and MADS model. In the next section, we present these both models.

\subsection{MADS Model}

MADS (Analysis Method of Dysfunctional Systems) model is a model of industrial risk analysis founded on the systemic approach [18]. This model is built on the basis of principles of the systemic modeling developed by [12]. It is composed of two systems called danger source system and target system. MADS model shows that the occurrence of any undesirable event passes by an events process. As shown in Figure 1, this process starts from a source of danger in the form of hazard flow and reaches a hazard target (target system).

MADS model presents a vocabulary which highlights a sequence of events: initiating event, initial event, flow of danger and final event. Therefore, with MADS model, the scenarios of risk are represented as a process of events, beginning with an initiating event in the system.

\subsection{UML Model}

UML model is a graphic modeling language in the field of software engineering, standardized by the OMG (Object Management Group). It became a standard of object modeling [19], which aims to build, to visualize, and to specify the information systems [20]. UML model includes a set of graphical notation techniques in order to create multiple views allowing expressing static, dynamic and functional aspect of the system (the different modeling diagrams are explained in detail in UML Notantion guide) [21].

UML model has been used in a wide variety of applications. In [18], the author uses UML language in order

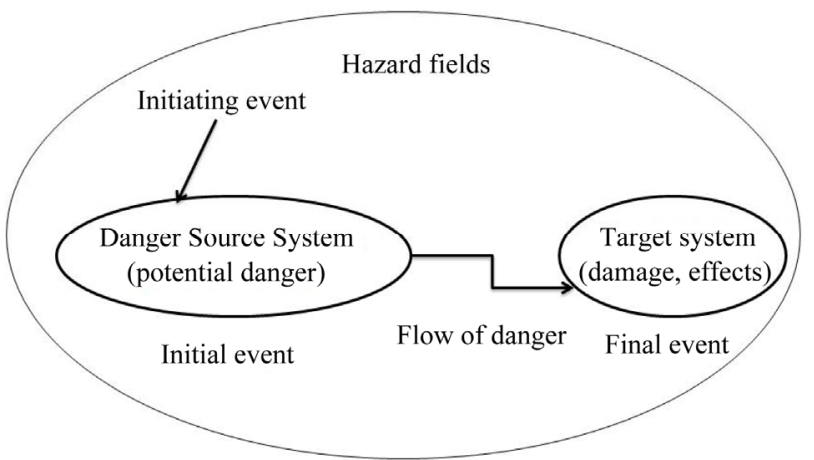

Figure 1. MADS model (Périlhon, 1999, adapted).

to model an information system of natural hazards. The authors in [22] propose a design for the plant safety model that is fully integrated within the plant lifecycle model using UML language. Reference [23] presents a model of railway system using UML in order to study its reliability. In [24], the authors use UML model in order to show the link between risk analysis and maintenance. In [25] a sequence diagram of UML is used to model the behavior of actors in a situation of decision-making. In [19], UML is used as an operational tool which formalizes the interactions within an industrial system and contributes to analyze its risks. In this paper, UML model comprises collaboration diagram is used to model scenarios of risk. The objective of collaboration diagram is to define the interactions with a dynamic point of view between the system objects. It represents these interactions through a chronological representation by sending messages between the objects in order to realize a function also called use case.

\section{Case Study}

The case study in this paper correspond to a storage unit of chemicals which belongs to an industry specialized in the manufacture of chemical substances for industrial use located in the industrial area in Casablanca (Morocco). This industry is part of an industrial group which is a global leader in the field of chemical specialty. For reasons of confidentiality, we do not quote its name. The storage unit studied in this paper corresponds to the warehouse. This unit contains three storage depots, corresponding to the three types of the stored materials, which are: monomers in liquid state, peroxides in solid state and flammable products in liquid state. The monomers are products presenting the risk of a polymerization which is strongly exothermic and can cause an explosion or a fire. The peroxides are characterized by their oxidizing and combustive properties. They can activate the combustion of a combustible substance. The flammable products have the characteristic to ignite in air and con- 
tinue to burn. Drums and containers are stored at temperatures specific to type of chemical product. Monomers must be stored in a temperature range between $16^{\circ}$ and $25^{\circ}$ to avoid polymerization or solidification of these materials. The temperature of peroxides should not exceed $30^{\circ}$, and the temperature of storage of the flammable products should not exceed $35^{\circ}$. Therefore, temperature in the warehouse is the important parameter to control. We consider the storage unit as a complex system composed of a set of components in interaction. Figure 2 presents a configuration of this system. Human factor has a level of responsibility on an adequate achievement of the storage. Procedures constitute an information support corresponding to the maintenance, the instructions of the products storage, the safety data sheets, the protection measures in case of an accidental spill of products, the safety check list, the location sheets, etc. Safety devices correspond to the prevention equipments (alarm, smoke detector, detector of temperature) and to the protection equipments (sprinkler, individual protection equipments). Regarding stored products, three types of chemical products are stored: monomers, peroxides, and flammable products and each type of chemical is stored in a specific temperature.

In this storage unit, four functionalities are defined:
- to store the products;

- to maintain the safety devices;

- to control the stored products;

- to control the temperature of storage.

These functions must be performed and all system components must be organized according to a goal which is to ensure an adequate storage of the products, by avoiding any situation being able to present a risk.

\section{Proposed Method and Application}

As previously mentioned the proposed model combines UML a We represent the danger source system of MADS model with the collaboration diagram (Figure 3) in order to define and model the scenarios of risk. We present these scenarios in the form of events process as defined in the MADS model. A scenario starts from an initiating event in the collaboration diagram which leads to an initial event.

The danger which flows from this initial event reaches target system causing a final event corresponding to damage and consequences.

In this paper, we present three examples of risk scenarios. Two scenarios in the function "to maintain the safety device" and a scenario in the function "to control the

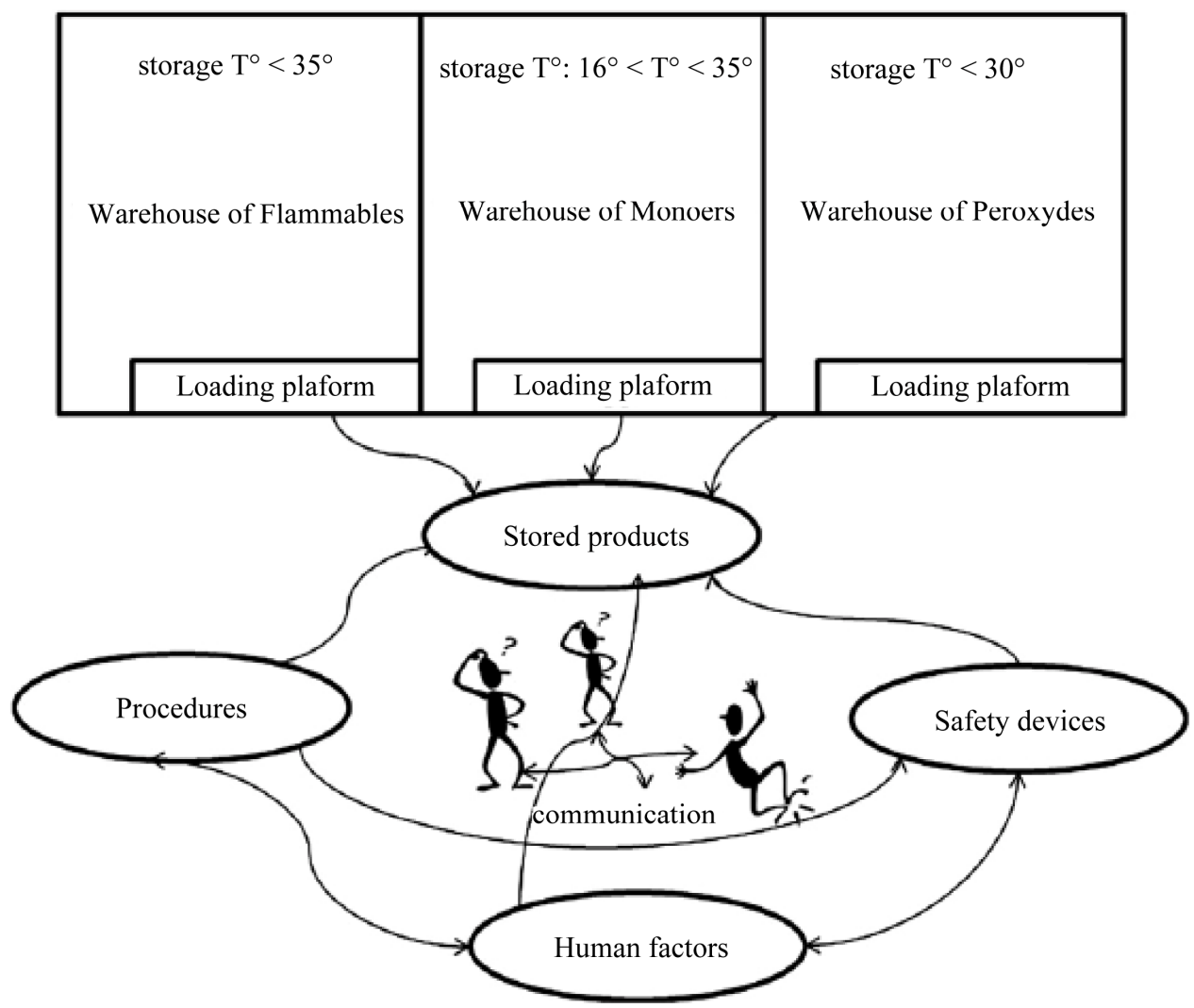

Figure 2. Schema showing a set of interactions in the system corresponding to storage unit of chemicals. 


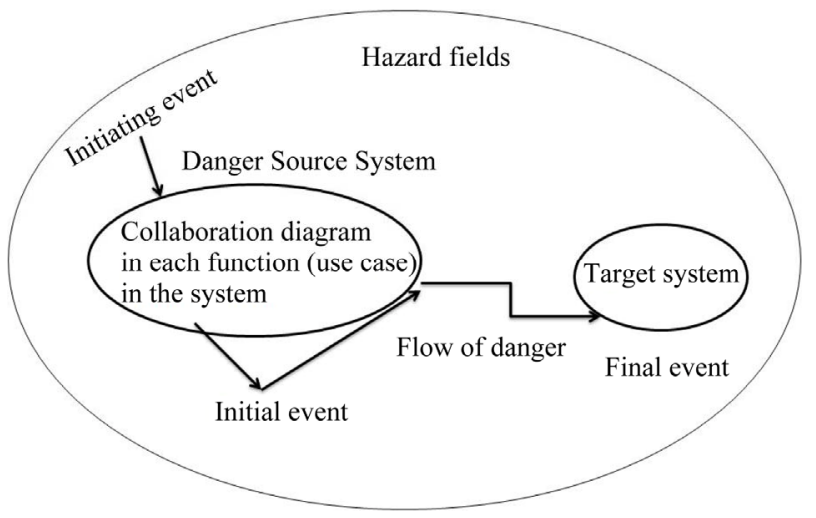

Figure 3. Proposed model founded on the MADS and UML model.

stored products”.

\subsection{Risk Scenario in the Function "to Control" the Stored Product}

Figure 4 shows this scenario which presents the case where operator of storage control did not pay attention to default corresponding to a degradation of storage shelves. The flow of danger associated to this no conforming action of operator is fall of storage containers which may lead to physical wounds or also an explosive atmosphere when it about a flammable product.

\subsection{Risk Scenarios in the Function "to Maintain Safety Device”}

This scenario (Figure 5) presents the case where the procedure of maintenance is not adequate. This irrelevance of the maintenance procedure leads to dysfunction of the safety equipments (i.e. temperature detector of storage). When the temperature of storage (i.e. monomers) exceeds the prescribed temperature, whereas it is not detected by the temperature detector, there is a risk of an exothermic reaction of the stored monomers, which can lead to an explosion.

Another scenario may be identified (Figure 6). For example the operator did not respect the procedure of maintenance, which is used to describe the instructions of reliable functioning of safety equipments (i.e. temperature detector of storage). This not conforming action of the operator can generate an inadequate functioning of the safety devices.

The risk scenarios represented with the method which combines MADS model and collaboration diagram allow defining the possible scenarios which generate risk, by

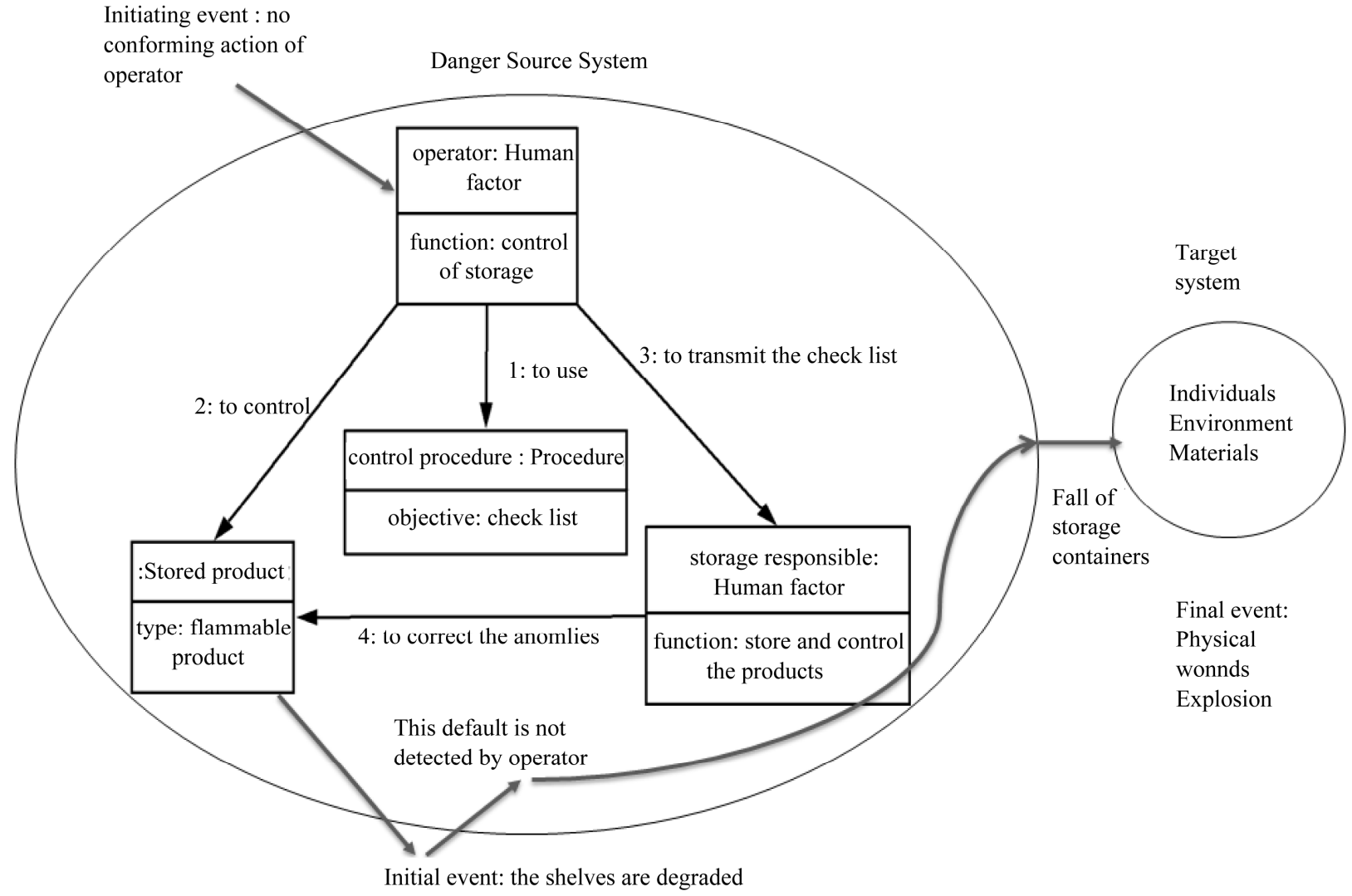

Figure 4. A scenario of risk in a function of storage control due to human error. 


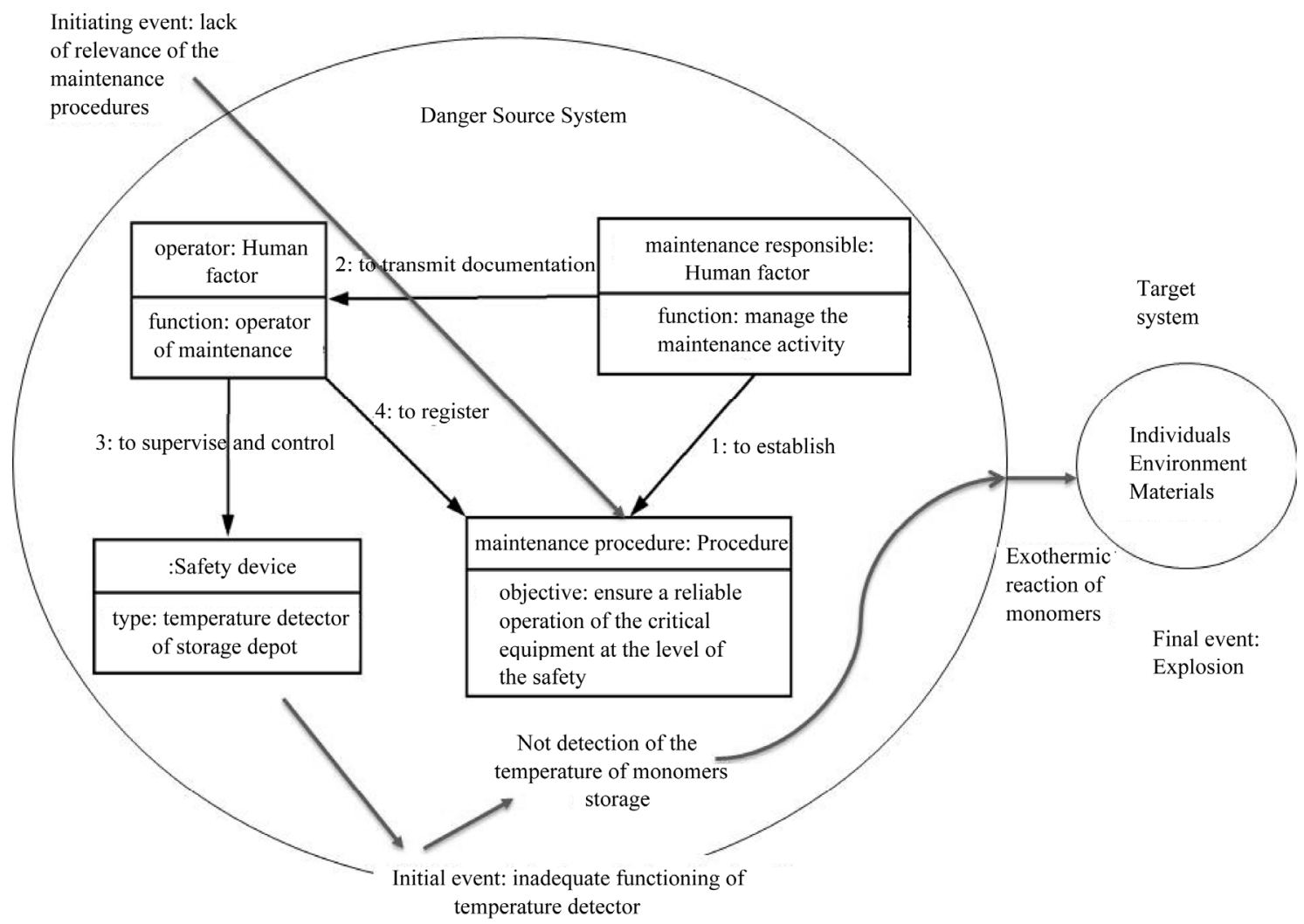

Figure 5. A scenario of risk in a function of maintenance due to use an inadequate procedures of maintenance.

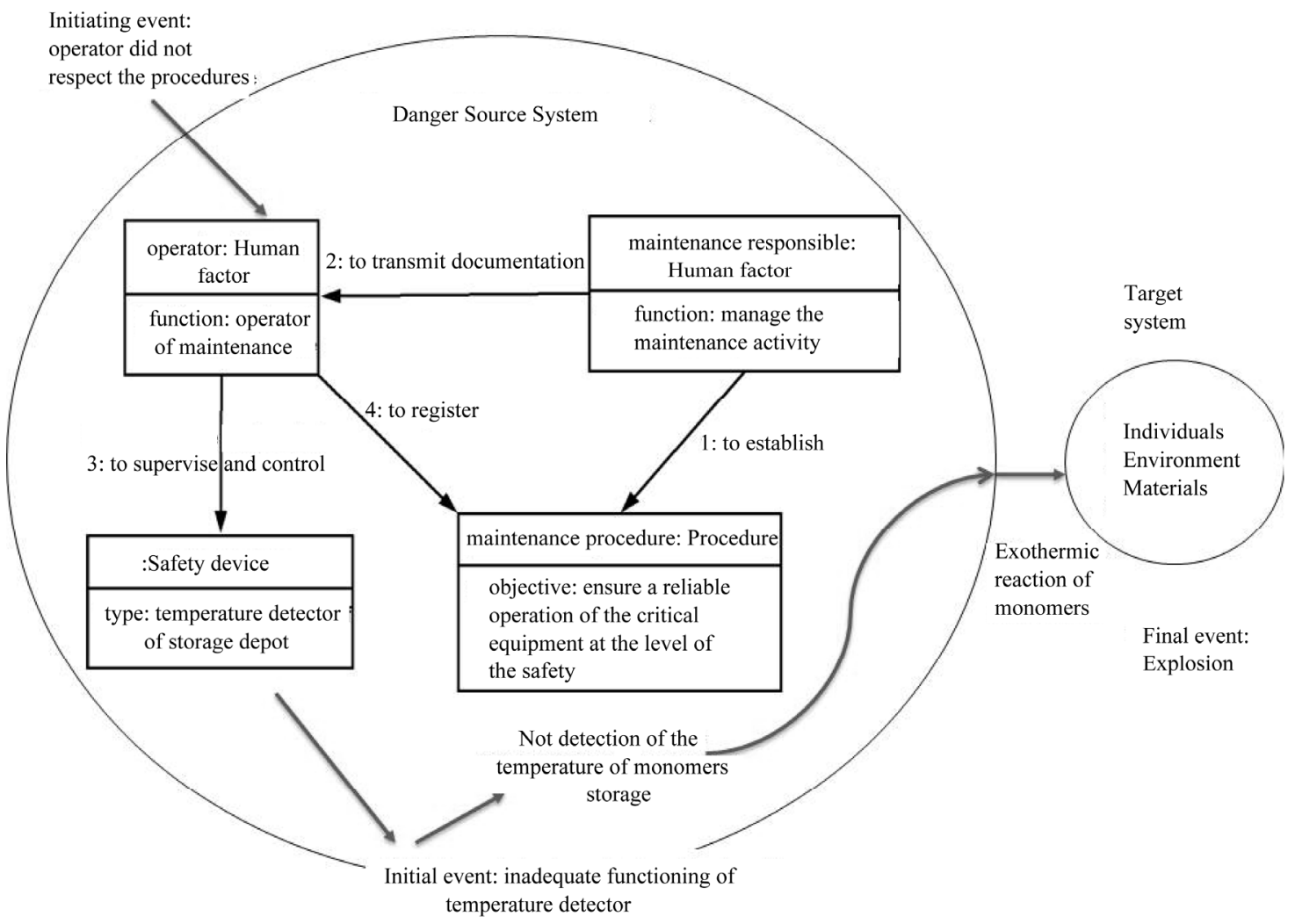

Figure 6. A scenario of risk in a function of maintenance due to inadequate behavior of operator. 
taking account of initiating events in the interacted components and in the each function of system.

\section{Conclusions}

The proposed method aims to integrate the UML model in the MADS model. Danger source system of MADS model is represented with collaboration diagram which make it possible to identify all possible scenarios at each function or use case of the system. It does specify the function of the system on which this scenario is identified, allowing a comprehensive identification of risk scenarios. This method presents several interests. It represents a mean to support the risk analysis with a systemic method taking into account the interactions between sytem components. In addition to risk analysis, this model is a particularly powerful tool that facilitates the understanding of the organization of an industrial system. This understanding is due to use of collaboration diagram which define the interactions between system components and these interactions are represented through a chronological representation by sending messages between the components in order to realize a function of the system.

The future work is to develop a computing platform which allows implementing this model.

\section{References}

[1] C. Cesics, "Introduction to Risk Analysis: Systematic Methods," Series of Publications of the Committee of Experts for Safety in the Chemical Industry, Notebook No. 4, 1981, pp. 1-8.

[2] C. Ccps, "Guidelines for Hazard Evaluation Procedure with Worked Examples,” 2nd Edition, CCPS AIChE, New York, 1992.

[3] A. Villemeur, "Reliability, Availability, Maintainability and Safety Assessment”, Vol. 1: Methods and Techniques, Vol. 2: Assessment, Hardware, Software and Human Factors, John Wiley, Hoboken, 1992.

[4] M. Monteau and M. Favaro, "Bilan des Méthodes D’Analyse a Priori Des Risques, Partie 2: Principales Méthodes de la Sécurité des Systèmes,” Cahiers des Notes Documentaires INRS, Vol. 139, 1990, pp. 363-389.

[5] F. Craweley, M. Preston and B. Tyler, "Hazop: Guide to Best Practice,” Institution of Chemical Engineers and European Process Safety Centre, Rugby, 1999.

[6] R. L. Rogers, "Methodology for the Risk Assessment of Unit Operations and Equipment for Use in Potentially Explosive Atmospheres," EU RASE Project n SMT4CT97, Library Area SAFETYNET, Inburex GmbH Hamm, 2000.

[7] Y. Mortureux, "Preliminary Risk Analysis,” Technical Engineering, Industrial Enterprise, Safety and Risk Management (CD Rom), 2002.
[8] A. Desroches, A. Leroy and F. Vallé, "Risk Management," Hermès and Lavoisier, Paris, 2003.

[9] J. Tixier, G. Dusserre, O. Salvi and D. Gaston, "Review of 62 Risk Analysis Methodologies of Industrial Plants," Journal of Loss Prevention in the Process Industries, Vol. 15, No. 4, 2002, pp. 2291-303.

[10] F. I. Khan and S. A. Abbasi, "Techniques and Methodologies for Risk Analysis in Chemical Process Industries," Journal of Loss Prevention in the Process Industries, Vol. 11, No. 4, 1998, pp. 261-277. doi:10.1016/S0950-4230(97)00051-X

[11] M. Nicolet-Monnier, "Integrated Regional Risk Assessment: The Situation in Switzerland," International Journal of Environment and Pollution, Vol. 6, No. 4-5, 1996, pp. 441-461.

[12] V. L. Bertalanffy, "General System Theory,” Dunod, Paris, 1993, p. 53.

[13] J. G. March and A. Herbert, “Organizations,” 2nd Edition, Blackwell Business, Cambridge, 1993.

[14] S. Sheard, "Definition of the Sciences of Complex Systems,” Insight INCOSE, Vol. 9, 2006, pp. 25-26.

[15] N. A. Leveson, "New Accident Model for Engineering Safer Systems,” Safety Science, Vol. 42, No. 4, 2004, pp. 237-270. doi:10.1016/S0925-7535(03)00047-X

[16] V. L. Bertalanffy, “General Systems Theory, Foundation, Development, Applications,” George Braziller, Inc., New York, USA, 1969.

[17] H. Bouloiz, E. Garbolino and M. Tkiouat, "Contribution of a Systemic Modeling Approach Applied to Support Risk Analysis of a Storage Unit of Chemical Products in Morocco," Journal of Loss Prevention in the Process Industries, Vol. 23, No. 2, 2009, pp. 312-322. doi:10.1016/j.jlp.2009.12.001

[18] A. Napoli, "Forest Fire Metrology: Methodological and Technological Approach to Support the Experimental Process in Forest Fire Behaviour Modelling," In Actes du Symposium International DELFI Feux de Forêts: Besoins et Innovations, Athènes, 1999, pp. 216-223.

[19] G. Booch, J. Rumbaugh and I. Jacobson, "The Unified Software Development Process,” Adisson-Wesley, New York, 2000.

[20] Object Management Group, UML 2.1 Superstructure Specification, Document: ptc/06-04-02, 2006.

[21] UML Notation guide, OMG, 2006. http://cgi.omg.org/uml/

[22] H. A. Gabbar, K. Suzuki and Y. Shimada, "Design of plant Safety Model in Plant Enterprise Engineering Environment," Journal of Reliability Engineering and System Safety, Vol. 73, No. 1, 2001, pp. 35-47. doi:10.1016/S0951-8320(01)00029-1

[23] J. L. Boulanger, P. Bon and G. Mariano, "Semi Formal Modeling and Formal Specification: UML \& B in Simple Railway Application,” International Conference on Software and Systems Engineering and their Applications, Toulouse, 12-14 October 2004.

[24] A. Mili, S. Basseto, A. Siadat and M. Tollenaere, "Dy- 
namic Risk Management Unveil Productivity Improvements," Journal of Loss Prevention in the Process Industries, Vol. 22, No. 1, 2008, pp. 25-34. doi:10.1016/j.jlp.2008.07.011

[25] A. Refsdal and K. Stolen, "Extending UML Sequence
Diagrams to Model Trust Dependent Behavior with the Aim to Support Risk Analysis,” Journal of Electronic Notes in Theoretical Computer Science, Vol. 197, No. 2, 2008, pp. 15-29. doi:10.1016/j.entcs.2007.12.014 